\title{
One in five patients with Duchenne muscular dystrophy dies from other causes than cardiac or respiratory failure
}

\author{
Lisa Wahlgren ${ }^{1,2}$ (D) Anna-Karin Kroksmark ${ }^{1,3} \cdot$ Mar Tulinius $^{1,2} \cdot$ Kalliopi Sofou $^{1,2}$
}

Received: 31 May 2021 / Accepted: 28 October 2021 / Published online: 21 November 2021

(c) The Author(s) 2021

\begin{abstract}
Duchenne muscular dystrophy (DMD) is a severe neuromuscular disorder with increasing life expectancy from late teens to over 30 years of age. The aim of this nationwide study was to explore the prevalence, life expectancy and leading causes of death in patients with DMD in Sweden. Patients with DMD were identified through the National Quality Registry for Neuromuscular Diseases in Sweden, the Swedish Registry of Respiratory Failure, pathology laboratories, neurology and respiratory clinics, and the national network for neuromuscular diseases. Age and cause of death were retrieved from the Cause of Death Registry and cross-checked with medical records. 373 DMD patients born 1970-2019 were identified, of whom 129 patients deceased during the study period. Point prevalence of adult patients with DMD on December 31st 2019 was 3.2 per 100,000 adult males. Birth prevalence was 19.2 per 100,000 male births. Median survival was 29.9 years, the leading cause of death being cardiopulmonary in $79.9 \%$ of patients. Non-cardiopulmonary causes of death $(20.1 \%$ of patients) mainly pertained to injury-related pulmonary embolism (1.3 per 1000 person-years), gastrointestinal complications (1.0 per 1000 person-years), stroke (0.6 per 1000 person-years) and unnatural deaths (1.6 per 1000 person-years). Death from non-cardiopulmonary causes occurred at younger ages (mean 21.0 years, SD $8.2 ; p=0.004)$. Age at loss of independent ambulation did not have significant impact on overall survival $(p=0.26)$. We found that non-cardiopulmonary causes contribute to higher mortality among younger patients with DMD. We present novel epidemiological data on the increasing population of adult patients with DMD.
\end{abstract}

Keywords Duchenne muscular dystrophy $\cdot$ Epidemiology $\cdot$ Prevalence $\cdot$ Survival $\cdot$ Neuromuscular $\cdot$ Cause of death

\section{Introduction}

Duchenne muscular dystrophy (DMD) is a rare neuromuscular disease with an estimated global birth prevalence of 19.8 per 100,000 live male births [1]. In western Sweden, the estimated prevalence is 21.5 per 100,000 school-aged boys [2]. DMD is caused by mutations in the dystrophin gene (Xp21.2) leading to total absence or nearly undetectable truncated levels of the dystrophin protein in skeletal

Lisa Wahlgren

lisa.wahlgren@vgregion.se

1 The Queen Silvia Children's Hospital, Sahlgrenska University Hospital, Gothenburg, Sweden

2 Department of Pediatrics, Institute of Clinical Sciences, Sahlgrenska Academy, University of Gothenburg, Gothenburg, Sweden

3 Department for Health and Rehabilitation/Physiotherapy, University of Gothenburg, Gothenburg, Sweden muscle $[3,4]$. Lack of dystrophin causes the muscle fibers to degenerate and be replaced with fat and connective tissue resulting in a progressive loss of muscle strength [5-7]. DMD leads to loss of ambulation before adolescence and, without treatment, life expectancy does not reach beyond late teens [8].

The two most common causes of death in DMD are respiratory and cardiac failure [9-11]. Chronic respiratory failure is attributed to weakness of the respiratory muscles and reduced chest wall compliance due to fibrotic changes of the chest wall muscles and scoliosis [12]. Weakness in expiratory muscles ultimately results in an increase in residual volume and decreased coughing ability. The lung compliance may also be affected because of micro-atelectatic changes [12]. Acute respiratory failure is common, often triggered by pneumonia or secretion stagnation. The heart is also affected by the lack of dystrophin, beginning with myocardial fibrosis in the left ventricular wall behind the mitral valve, to eventually affect the entire left ventricle 
[13]. Dilated cardiomyopathy is the most common cardiac involvement in patients with DMD [14], and increases the risk of premature death [15].

Improved care with corticosteroid therapy, respiratory care, prevention and treatment of cardiomyopathy and scoliosis treatment has had a positive impact on both life expectancy and the course of the disease [10, 11, 16-20]. Treatment with corticosteroids has been shown to slow down the disease progression with respect to muscle strength, motor function including ambulation, scoliosis and pulmonary function [16, 21-24]. Timely initiation of non-invasive mechanical ventilation, along with mechanical insufflationexsufflation and early cardio- protection have been associated with an increasing longevity of a median life span over 30 years [19].

To date, there are limited studies on the evolution of natural history and causes of death in DMD, mainly restricted to small patient populations and specialized neuromuscular clinics $[10,11,17-19]$. The aim of this nationwide study was to explore the prevalence, life expectancy and leading causes of death in patients with DMD in Sweden.

\section{Materials and methods}

\section{Study population}

All male patients born since 1st January 1970 who died by 31st December 2019 and were followed at a medical clinic in Sweden with a confirmed diagnosis of DMD were included in the study. The diagnostic criteria applied were typical clinical phenotype of DMD with elevated serum creatine kinase and either (i) muscle biopsy findings compatible with DMD or (ii) pathogenic DMD variants in the dystrophin gene or (iii) confirmed DMD diagnosis in a maternal relative. A typical clinical phenotype was defined as symptom onset before 5 years of age and loss of ambulation before 13 years of age [25]. Since corticosteroid treatment has shown a 3-year delay in loss of ambulation [24], patients who had received corticosteroids and lost ambulation before 16 years of age were considered eligible for inclusion, if fulfilling the diagnostic criteria mentioned above. Patients were excluded from the study if they had an intermediate form between DMD and Becker muscular dystrophy (BMD) defined as loss of ambulation between 13 and 16 years of age without corticosteroid treatment, or BMD defined as loss of ambulation above 16 years of age, or any other form of muscular dystrophy.

\section{Sources used to identify the study population}

Patients were identified via the National Quality Registry for Neuromuscular Diseases in Sweden (NMiS), The Swedish
Registry of Respiratory Failure (Swedevox) and all pathology laboratories performing skeletal muscle biopsies in Sweden, i.e. the Sahlgrenska University Hospital in Gothenburg, the Karolinska University Hospital in Stockholm and the University Hospitals in Linköping, Umeå, Uppsala and Lund, which represent the six health care regions in Sweden. In addition, patients were identified through an inquiry to all neurology and respiratory clinics in Sweden, as well as the national network of clinicians working with neuromuscular diseases in Sweden. A pilot study for patients with DMD deceased between 2000-2010 in Sweden was also used [26]. The Cause of Death Registry at the Swedish National Board of Health and Welfare was used to retrieve information on identified patients regarding the date and cause of death (Fig. 1; Flowchart, inclusion process).

\section{Data collection}

Data was collected from the patients' medical records in a systematic manner with the use of a case report form, which is available upon request. Data included clinical features at onset and during the disease course, age at diagnosis, serum $\mathrm{CK}$ at diagnosis, age at loss of ambulation, muscle biopsy findings, genetic findings, family history, corticosteroid treatment as well as age and cause of death. All medical records were reviewed by two pediatric neurologists with expertise in neuromuscular disorders.

\section{Data collection for epidemiological analyzes}

For patients who were alive by the end of 2019, confirmation of DMD diagnosis was performed for calculation of prevalence and survival analyses. The diagnosis was verified through the NMiS registry and/or through the pathology reports if the latter matched the inclusion criteria, otherwise the medical records were used for confirmation. Data with estimates of the Swedish population were collected from Statistics Sweden, www.scb.se/en. There were 2,711,935 live male births over a period of 50 years (1970-2019). Between 1970-79 there were 537,089 live male births, in 1980-89 there were 515,590 , in $1990-99$ there were 547,704 , in 2000-09 there were 521,728 and in 2010-19 there were 589,824 . The Swedish adult male population,18-99 years of age, alive and at risk at the end of 2019 was 4,073,160.

\section{Leading cause of death}

For all deceased patients in Sweden, the cause(s) of death are registered at the Cause of Death Registry at the Swedish National Board of Health and Welfare. To ensure consistency and accuracy in our study, we cross-checked the Cause of Death Registry against patients' medical records. In the event of discrepancies, we based the leading cause of death 


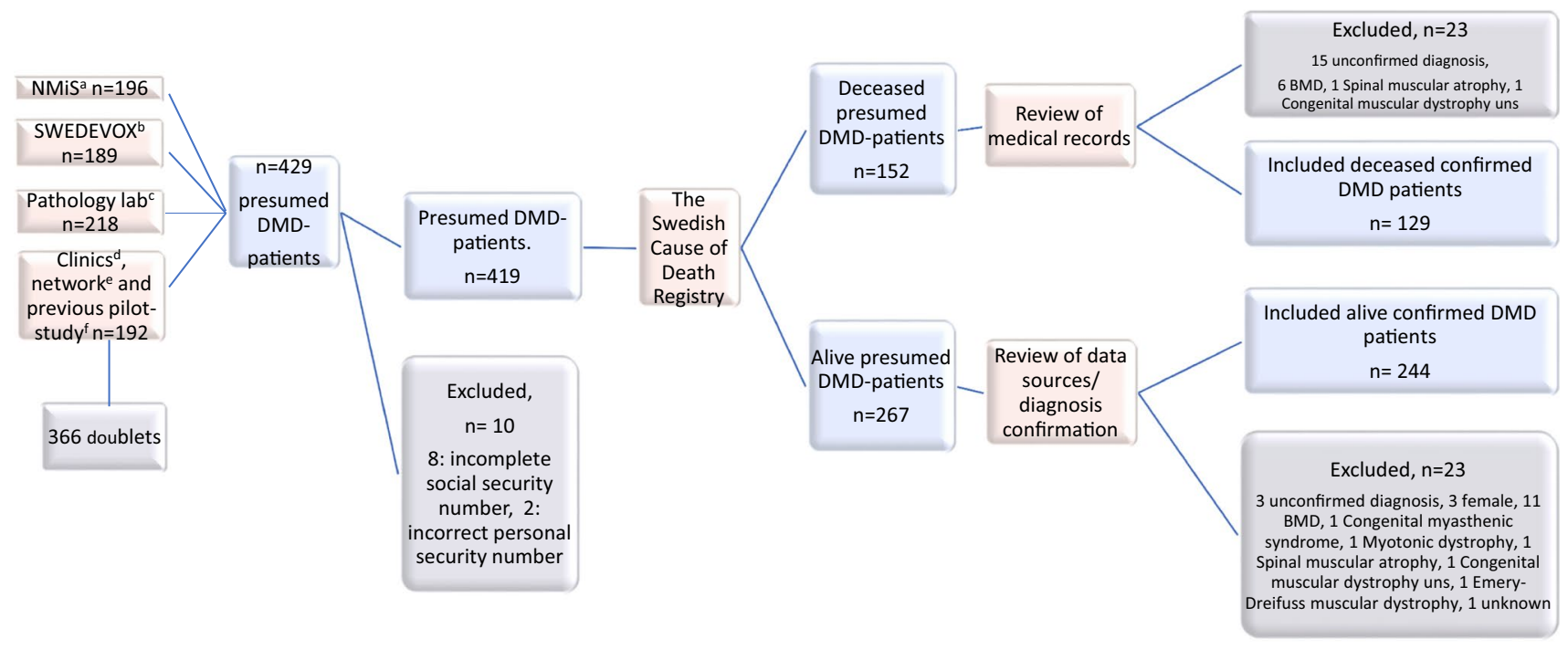

Fig. 1 Flowchart: Identification and inclusion procedure of the Swedish patients with DMD born 1970-2019. Patients identified through: a the National Quality Registry for Neuromuscular Diseases in Sweden (NMiS.) b the Swedish Registry of Respiratory Failure (Swedevox) c all pathology laboratories analyzing skeletal muscle biop-

on that reported in the medical records. In the event of multiple conditions contributing to death, the most prominent condition leading to death was defined as the leading cause of death. In the event of sudden death at home without any other apparent causes contributing to death (i.e. ventilator malfunction, infection etc.), 'cardiac arrest' was reported as the leading cause of death. In the event of accidental or nonaccidental injury or poisoning leading to death in connection with the incident this was documented as 'unnatural cause of death' (International Classification of Diseases- ICD 10). When the leading cause of death was only based on the Cause of Death Register (i.e. not verified via patient's medical records), this was documented as 'non-verified'. For those not verified in the medical records and poorly described in the Cause of Death Registry, the cause of death was documented as 'unknown'.

\section{Statistical analysis}

Continuous variables are presented with mean and standard deviations (SD) and median and quartile 1 (25\%) and quartile $3(75 \%)$ (Q1;Q3). Categorical variables are presented with numbers and percentages. All analyzes were assessed with non-parametric tests. Jonckheere-Terpsta Test was used to analyze the trends over the decades regarding age at diagnosis, age at loss of ambulation (the patients never learning to walk due to other reasons (i.e. cerebral palsy) were excluded in the analyzes) and age at start with corticosteroids. Birth prevalence was calculated as the number of patients diagnosed with DMD during each decade, i.e. sies in Sweden d. an inquiry to all neurology clinics and pulmonary clinics in Sweden e. the Swedish neuromuscular network. $\mathbf{f}$ a pilot study for patients with DMD deceased between 2000 and 2010 [26]. $\mathrm{DMD}=$ Duchenne muscular dystrophy, $\mathrm{BMD}=$ Becker muscular dystrophy, $\mathrm{n}=$ number

1970-79, 1980-89, 1990-99, 2000-09 and 2010-19 in relation to the total live male births during the same decade. The estimated birth prevalence was divided by the previously estimated prevalence in western Sweden presented by Darin and Tulinius [2]. This is presented as 'percent of calculated birth prevalence'. Point prevalence for the adult population, born 1970 or later, was calculated as the number of patients with DMD over 18 years of age and known to be alive on December 31st 2019, in relation to the total male population 18-99 years of age in Sweden known to be alive on December 31st 2019. Survival data for the total population, the population divided into decades of birth and the population divided into the six health care regions in Sweden, were described by Kaplan-Meier-curves and analyzed by the Log-Rank test. To ensure that we had a representative population from each study decade we used the 'percent of calculated birth prevalence', as defined above. If the percent were under $80 \%$ the population of this study decade was considered as non-representative and thus excluded from the survival analyzes. Patients who were alive at the end of the study period were censored. The incidence of noncardiopulmonary causes of death was calculated as number of cases divided by the study population in person-years. The Fisher's Non Parametric Permutation Test was used to analyze differences in age between cardiopulmonary causes of death and non-cardiopulmonary. Mean age difference with $95 \%$ confidence interval is given. For comparison of non-cardiopulmonary causes of death over the three ageclasses $<20,20-30$ and $>30$ years of age the Mantel-Haenszel Chi Square test was used. All significance tests were 
two-sided and conducted at the 5\% significance level. Analysis was made using IBM SPSS statistics 25 (C Copyright IBM Corporation 1994, 2021).

\section{Ethical considerations}

The study protocol was approved by the Swedish Ethics Committee (Dnr. 1130-11 and 2019-01,790).

\section{Results}

\section{Study population}

We identified 129 patients with DMD who were born between 1970 and 2019 and deceased during the same time period (Fig. 1; Flowchart, inclusion process). Patient demographics are presented in Table 1, along with population distribution across decades. Diagnosis was based on muscle biopsy findings in $108(84 \%)$, genetic findings in $45(35 \%)$ and family history for DMD in 38 (33\%) of the patients. There was no change over time regarding the age at diagnosis $(p=0.72)$ or the age at loss of ambulation $(p=0.49)$. There was a significant decrease in the age at start of corticosteroid treatment between patients born 1970-79 and 1990-99 $(p=0.023)$ and between patients born 1980-89 and 1990-99 $(p<0.001)$.
Table 2 Epidemiology of Swedish DMD patients (alive and deceased), born 1970-2019

\begin{tabular}{|c|c|c|c|}
\hline & Total n & Deceased n (\%) & $\begin{array}{l}\text { Birth prevalence } \mathrm{x} \text { per } \\
100,000(\% \text { of calculated birth } \\
\left.\text { prevalence }^{\mathrm{a}}\right)\end{array}$ \\
\hline \multicolumn{4}{|c|}{ Total population born: } \\
\hline 1970-2019 & 373 & $129(34.6 \%)$ & $\begin{array}{l}13.8 \text { per } 100,000 \\
(64.2 \%)\end{array}$ \\
\hline \multicolumn{4}{|c|}{ Population divided in birth decades: } \\
\hline 1970-1979 & 31 & $26(83.9 \%)$ & $\begin{array}{l}5.8 \text { per } 100,000 \\
(27.0 \%)\end{array}$ \\
\hline 1980-1989 & 99 & $63(63.6 \%)$ & $\begin{array}{l}19.2 \text { per } 100,000 \\
(89.3 \%)\end{array}$ \\
\hline 1990-1999 & 112 & $37(32.7 \%)$ & $\begin{array}{l}20.5 \text { per } 100,000 \\
(95.3 \%)\end{array}$ \\
\hline 2000-2009 & 94 & $3(3.2 \%)$ & $\begin{array}{l}18.0 \text { per } 100,000 \\
(83,7 \%)\end{array}$ \\
\hline 2010-2019 & 37 & $0(0.0 \%)$ & $\begin{array}{l}6.3 \text { per } 100,000 \\
(29.3 \%)\end{array}$ \\
\hline \multicolumn{4}{|c|}{ Population used for survival analyses: } \\
\hline 1980-2009 & 305 & $103(33.8 \%)$ & $\begin{array}{l}19.2 \text { per } 100,000 \\
(89.3 \%)\end{array}$ \\
\hline
\end{tabular}

${ }^{\text {a }}$ based on the study by Darin and Tulinius [2], with 21.5 per 100,000 school-aged boys in the western Sweden

$\mathrm{DMD}=$ Duchenne muscular dystrophy, $\mathrm{n}=$ number

Table 1 Demographics of Swedish deceased DMD patients, born 1970-2019

\begin{tabular}{|c|c|c|c|c|c|}
\hline & \multirow{2}{*}{$\begin{array}{l}\text { Total population } \\
\text { 1970-2019 } \\
\mathrm{n}=129\end{array}$} & \multicolumn{4}{|l|}{ By decade of birth } \\
\hline & & $\begin{array}{l}1970-1979 \\
\mathrm{n}=26\end{array}$ & $\begin{array}{l}1980-1989 \\
\mathrm{n}=63\end{array}$ & $\begin{array}{l}1990-1999 \\
\mathrm{n}=37\end{array}$ & $\begin{array}{l}2000-2009 \\
\mathrm{n}=3\end{array}$ \\
\hline Age at diagnosis ( $n$ ) & 123 & 25 & 59 & 36 & 3 \\
\hline mean (SD), y & $4.83(1.74)$ & $4.85(2.08)$ & $4.94(1.52)$ & $4.50(1.80)$ & $6.29(1.95)$ \\
\hline Median (Q1;Q3), y & $4.61(3.41 ; 6.09)$ & $4.58(3.26 ; 6.18)$ & $4.93(3.90 ; 6.24)$ & $4.36(3.15 ; 5.87)$ & $7.00(4.09 ; 7.79)$ \\
\hline Age at $\operatorname{LoA}(n)$ & 127 & 26 & 61 & 37 & 3 \\
\hline mean (SD), y & $10.29(2.08)$ & $10.46(1.86)$ & $9.91(2.02)$ & $10.84(2.32)$ & $10.00(0.50)$ \\
\hline Median (Q1;Q3), y & $10.00(9.00 ; 11.90)$ & $10.65(9.00 ; 12.00)$ & $10.00(8.50 ; 11.00)$ & $11.00(9.20 ; 12.00)$ & $10.00(9.50 ; 10.50)$ \\
\hline $\begin{array}{l}\text { Treated with } c c \\
\mathrm{~N}(\%)\end{array}$ & $76(64.4 \%)$ & $5(21.7 \%)$ & $36(64.3 \%)$ & $32(88.9 \%)$ & $3(100 \%)$ \\
\hline Age at start cc $(n)$ & 63 & 5 & 29 & 27 & 2 \\
\hline mean (SD), y & $7.55(3.95)$ & $14.64(7.11)$ & $8.44(2.93)$ & $5.36(2.03)$ & $6.41(3.15)$ \\
\hline Median (Q1;Q3), y & $6.49(5.06 ; 9.12)$ & $13.48(12.93 ; 17.09)$ & $7.52(6.34 ; 10.53)$ & $5.67(3.92 ; 6.46)$ & $6.41(4.18 ; 8.64)$ \\
\hline Age at death (n) & 129 & 26 & 63 & 37 & 3 \\
\hline mean (SD), y & $24.38(7.06)$ & $30.67(8.22)$ & $24.75(5.64)$ & $20.12(4.41)$ & $14.50(2.03)$ \\
\hline Median (Q1;Q3), y & $24.34(19.16 ; 28.56)$ & $30.31(25.34 ; 37.74)$ & $25.49(20.72 ; 28.03)$ & $19.85(17.90 ; 22.09)$ & $14.41(13.46 ; 15.49)$ \\
\hline
\end{tabular}

$\mathrm{DMD}=$ Duchenne muscular dystrophy, $\mathrm{n}=$ number, $\mathrm{SD}=$ standard deviation, $\mathrm{y}=$ years $\mathrm{Q}=$ quartile, $\mathrm{LoA}=$ loss of ambulation, $\mathrm{cc}=\mathrm{corticoster}-$ oids 


\section{Epidemiology}

By December 31st 2019, a total of 373 patients born since 1970 with confirmed DMD were identified (Table 2). The DMD population born during the period 1980-2009, i.e. after removing the first and last study decades as non-representative for the entire DMD population, was estimated at 305 patients, representing a birth prevalence of 19.2 per 100,000 live male births. The number of adult patients with DMD in Sweden who were alive on December 31st 2019 was 130 patients, accounting for a point prevalence of 3.2 per 100,000 adult males.

\section{Life span}

The median survival was 29.9 years of age $(95 \%$ CI $27.1-31.2$ ) with $75 \%$ of patients surviving to 23.6 years of age and $25 \%$ of patients surviving to 36.5 years of age (Fig. 2; population born 1980-2009). For patients born 1980-89, the median survival was 29.6 years (95\% CI 26.5-32.3) with $75 \%$ of patients surviving to 24.1 years and $25 \%$ of patients surviving to 36.5 years of age. For patients born between 1990-99 and 2000-09, the median age was not calculated since more than $50 \%$ of the patients were still alive on December $31^{\text {st }} 2019$ (Fig. 3; population born 1980-2009). The decade-by-decade survival estimations for the DMD population born 1980-2009 did not differ $(p=0.92)$. When analyzing the six healthcare regions of Sweden separately for patients born 1980-2009, the median survival ranged from 26.0 (95\% CI 19.1-32.9) to 33.0 (95\% CI 27.5-38.5) years of age, with no significant differences except for the Southern region that showed the highest survival. There was no correlation between the age at loss of ambulation and the age at death (Spearman rho $=0.10$, $p=0.26$ ). There was neither any difference in the age at death between patients losing their ambulation before or after ten years of age $(p=0.52)$.

\section{Cause of death}

The most frequent leading cause of death was cardiac complications (41.9\%) (95\% CI 33.2-50.9) with a mean age of 26.2 (SD 6.3) years, followed by respiratory failure (38.0\%) (95\% CI 29.6-46.9) with a mean age of 24.2 (SD 6.6) years. Non-cardiopulmonary complications were the leading causes of death in $20.1 \%$ (95\% CI 13.6-28.1) of the patients, including: infections (other than pneumonia or myocarditis), stroke, injury-related pulmonary embolism, gastrointestinal complications and unnatural causes (Table 3; population born 1970-2019). Infections as the leading cause of death had an incidence of 1.6 per 1000 person-years, stroke 0.6 per 1000 person-years, injury-related pulmonary embolism 1.3 per 1000 person-years, gastrointestinal complications 1.0 per 1000 person-years, and unnatural causes of death 1.6 per 1000 person-years. Thromboembolic events (including pulmonary embolism and ischemic cerebral infarction) as the leading cause of death had an incidence of 1.6 per 1000 person-years. Death from non-cardiopulmonary complications (mean age 21.0 (SD 8.2) years) occurred in younger age than death from cardiopulmonary complications (mean age 25.2 (SD 6.5) years), with a mean difference of 4.3 years $(95 \%$ CI 1.4-7.3) ( $p=0.004)$, (Fig. 4; population born 1970-2019).
Fig. 2 Kaplan-Meier curve for survival estimate for Swedish patients with DMD, born 1980-2009. (including alive patients censored on 31st December 2019). Median survival 29.9 years of age $(95 \%$ CI 27.1-31.2). Shaded blue area indicates the $95 \%$ confidence interval. $\mathrm{DMD}=$ Duchenne muscular dystrophy, $\mathrm{CI}=$ Confidence Interval

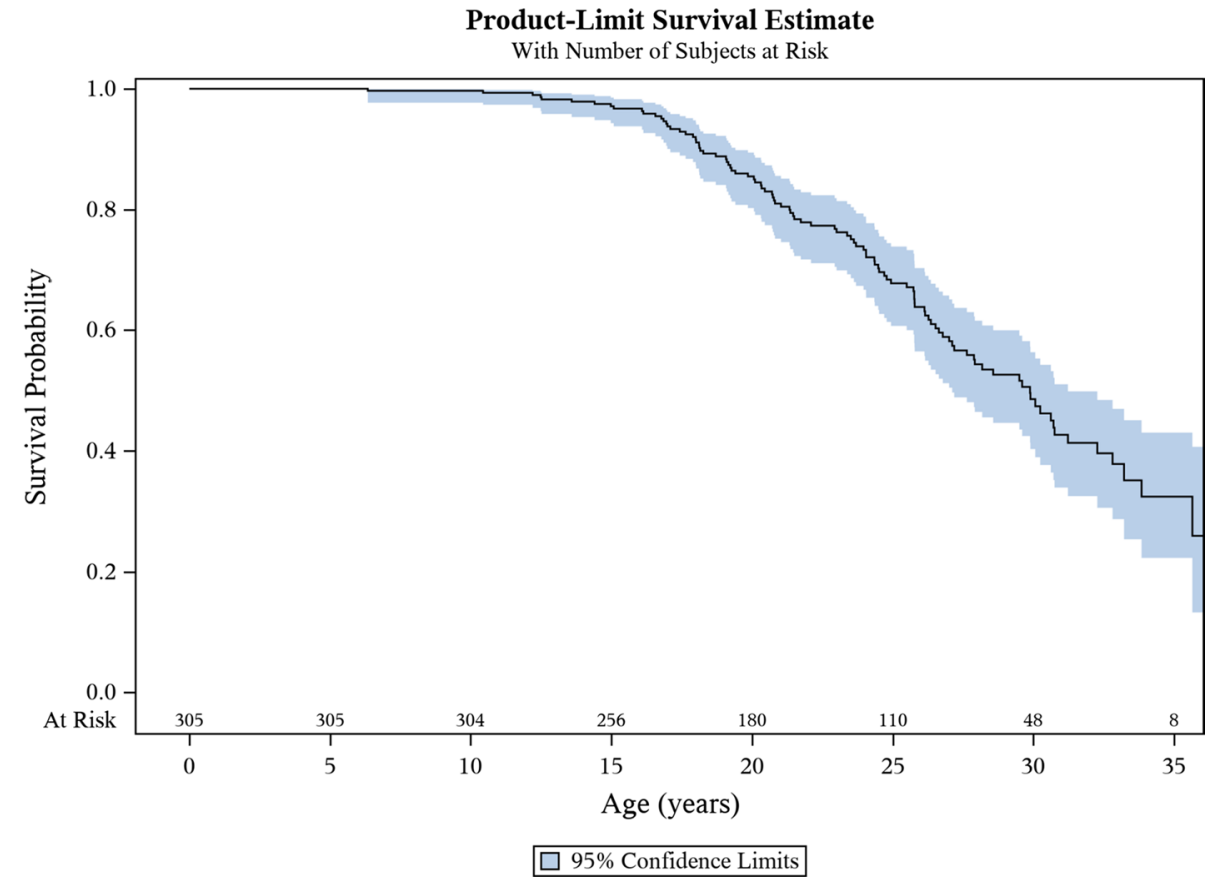


Fig. 3 Kaplan-Meier curve for survival estimate for Swedish patients with DMD presented per birth decades for population born 1980-2009. (including alive patients censored on 31st December 2019). Shaded areas indicate the $95 \%$ confidence interval. Median survival for patients born 1980-89 was 29.6 years of age $(95 \% \mathrm{CI}$ 26.5-32.3). DMD = Duchenne muscular dystrophy, $\mathrm{CI}=$ Confidence Interval

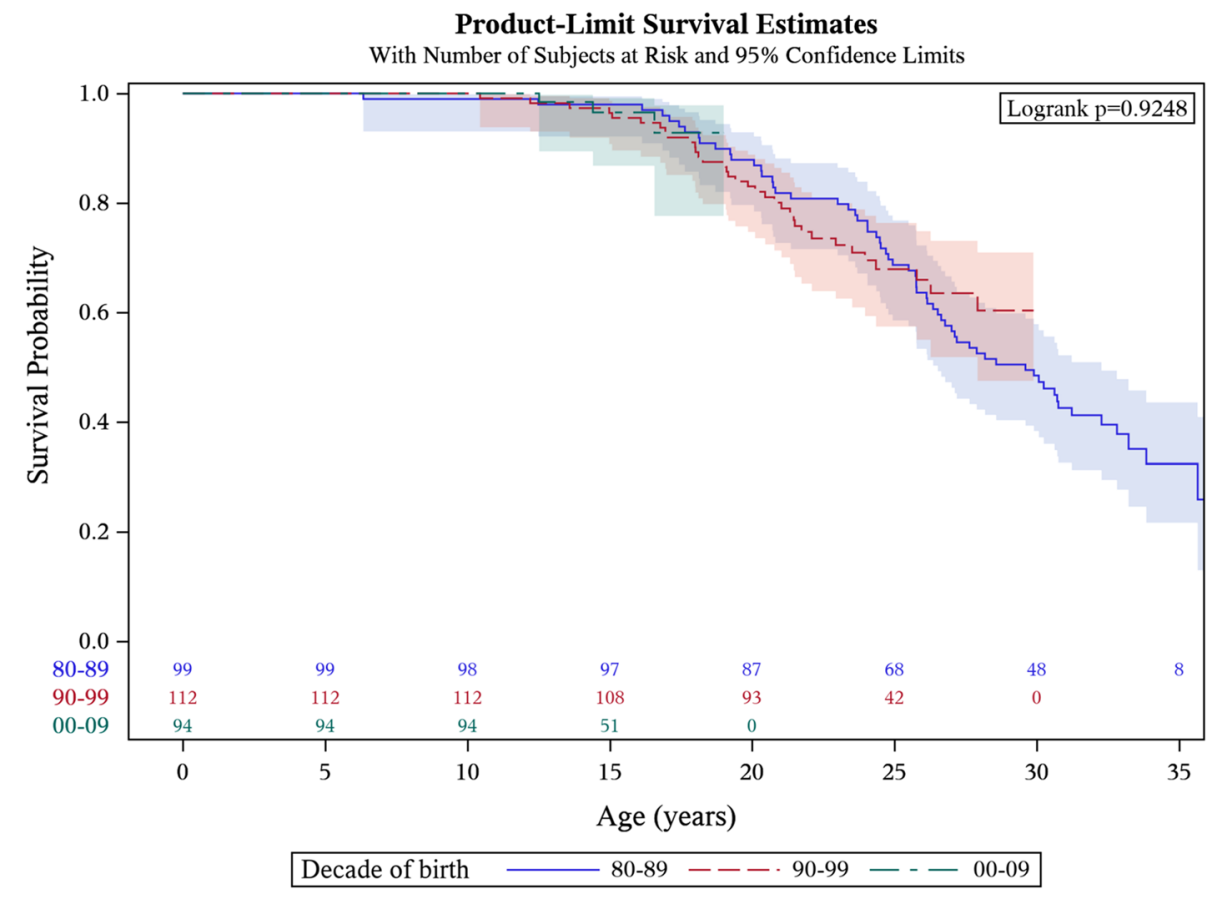

Non-cardiopulmonary causes of death were more common for patients under 20 years of age $(37.8 \%)$ than for patients between 20-30 (15.2\%) $(p=0.019)$ and patients over 30 years of age (7.7\%) $(p=0.012)$ (Fig. 5; population born 1970-2019). Accidental/non-accidental injury, injuryrelated pulmonary embolism and stroke as leading causes of death were only present in patients under 25 years of age.

\section{Discussion}

Our study is one of few nationwide studies to explore the prevalence, life expectancy and leading causes of death in patients with DMD over the past half century. We estimated the birth prevalence of DMD in Sweden to be 19.2 per 100000 males. Our results confirm previous findings that patients with DMD present an increasing longevity. In our study, the median survival was 29.9 years of age. We found that the age at loss of independent ambulation did not have a significant impact on the overall survival. Cardiac and respiratory failure were the leading causes of death in approximately $80 \%$ of our study population. Our study revealed that one in five patients with DMD dies of noncardiopulmonary causes, and that these causes significantly contribute to higher mortality rates among younger patients with DMD.

We identified four main groups of non-cardiopulmonary causes of death in our study; stroke (2/129 pts); injuryrelated pulmonary embolism (4/129 pts); gastrointestinal complications (3/129 pts) and unnatural causes of death (5/129 pts). It has been postulated that patients with DMD are at increased risk of thromboembolic events such as cerebral infarctions, deep vein thrombosis and pulmonary embolism, mainly attributed to chronic immobility and underlying cardiac insufficiency [27]. The incidence of thromboembolic events leading to death in our study was estimated to be 1.6 per 1000 person-years (5/129 pts; 3.9\%), which is higher than the annual incidence of 57.2 per 100.000 reported in the general population [28]. The incidence of stroke was 0.6 per 1000 person-years $(2 / 129$ pts; $1.5 \%)$. This is lower than the incidence of ischemic stroke reported in previous studies (0.75-1 per 100 person-years) [29, 30], but notably higher than the incidence found in the Swedish male population under 45 years of age (7.5-11.4 per 100 000) [31]. In addition to the fact that gastrointestinal complications were one of the main non-cardiopulmonary causes of death in our study, gastrointestinal symptoms were reported by Parker et al. as the most commonly reported complaints after orthopedic, respiratory, cardiac and cognitive comorbidities [32]. The incidence of unnatural causes of death in our cohort was 1.6 per 1000 person-years (5/129 pts; 3.9\%). Our study is the first to unveil the occurrence of unnatural causes of death and their important effect on mortality in DMD at younger ages.

Cardiac complications were the most frequent leading cause of death in our cohort, with an incidence of 17.2 per 1000 person-years (54/129 pts; $41.9 \%)$. Death from cardiac complications occurred later compared to other causes of death, at a mean age of 26 years. There is increasing evidence of a shift in the natural history of DMD to longer life span and death from end-stage heart failure [11]. To our knowledge, our study is the first to present the shift of 
Table 3 Causes of death ${ }^{\mathrm{a}}$ in Swedish deceased DMD patients, born 1970-2019

\begin{tabular}{|c|c|c|c|}
\hline & & $\mathrm{n}(\%)$ & $\begin{array}{l}\text { Incidence per } \\
1000 \text { person- } \\
\text { years }\end{array}$ \\
\hline \multicolumn{4}{|l|}{ Respiratory } \\
\hline \multirow[t]{5}{*}{ Acute respiratory failure } & Infection & $18(14 \%)$ & 5.8 \\
\hline & Pneumothorax & $2(1.6 \%)$ & 0.6 \\
\hline & Secretion stagnation & $4(3.1 \%)$ & 1.3 \\
\hline & Ventilator error & $1(0.8 \%)$ & 0.3 \\
\hline & UNS & $6(4.7 \%)$ & 1.9 \\
\hline Chronic respiratory failure & Chronic respiratory failure & $18(14.0 \%)$ & 5.8 \\
\hline \multicolumn{4}{|l|}{ Cardiac } \\
\hline \multirow[t]{3}{*}{ Heart failure } & Dilated cardiomyopathy & $27(20.7 \%)$ & 8.8 \\
\hline & Cardiomyopathy UNS & $1(0.8 \%)$ & 0.3 \\
\hline & Arrythmia & $2(1.6 \%)$ & 0.6 \\
\hline Myocardial infarction & Myocardial infarction & $2(1.6 \%)$ & 0.6 \\
\hline \multirow[t]{4}{*}{ Cardiac arrest } & Arrythmia & $5(3.9 \%)$ & 1.6 \\
\hline & Sudden death & $10(7.8 \%)$ & 3.2 \\
\hline & Related to pneumonia & $1(0.8 \%)$ & 0.3 \\
\hline & UNS & $5(3.9 \%)$ & 1.6 \\
\hline Myocarditis & Myocarditis & $1(0.8 \%)$ & 0.3 \\
\hline \multicolumn{4}{|l|}{ Infection } \\
\hline & Peritonitis & $1(0.8 \%)$ & 0.3 \\
\hline & Sepsis & $1(0.8 \%)$ & 0.3 \\
\hline & Pancreatitis & $1(0.8 \%)$ & 0.3 \\
\hline & Gastroenteritis & $1(0.8 \%)$ & 0.3 \\
\hline & UNS & $1(0.8 \%)$ & 0.3 \\
\hline \multicolumn{4}{|l|}{ Stroke } \\
\hline & Ischemic cerebral infarction & $1(0.8 \%)$ & 0.3 \\
\hline & Subarachnoidal hemorrhage & $1(0.8 \%)$ & 0.3 \\
\hline \multicolumn{4}{|l|}{ Pulmonary embolism } \\
\hline & Injury-related & $4(3.1 \%)$ & 1.3 \\
\hline \multicolumn{4}{|l|}{ Other } \\
\hline & Intestinal volvulus & $2(1.6 \%)$ & 0.6 \\
\hline & Gastrointestinal hemorrhage & $1(0.8 \%)$ & 0.3 \\
\hline & Acute kidney failure & $1(0.8 \%)$ & 0.3 \\
\hline & Cancer & $1(0.8 \%)$ & 0.3 \\
\hline & Post-surgery complications & $1(0.8 \%)$ & 0.3 \\
\hline & UNS & $4(3.1 \%)$ & 1.3 \\
\hline \multicolumn{4}{|l|}{ Unnatural } \\
\hline & Accidental/non-accidental & $5(3.9 \%)$ & 1.6 \\
\hline
\end{tabular}

${ }^{a}$ In $83.7 \%$ of the patients the leading causes of death were verified through the medical records. Of the remaining 21 patients $(16.3 \%)$, the leading cause of death was only based on the Cause of Death Register (non-verified) in 19 patients and was documented as unknown in 2 patients. Generated person-years in deceased group was 3082 years

$\mathrm{DMD}=$ Duchenne muscular dystrophy, $\mathrm{UNS}=$ unspecified cardiac-related mortality towards older ages compared with mortality due to respiratory failure $[10,18]$. Improvements in respiratory care and assisted ventilation over the years, as well as the introduction of cardio-protection are considered major contributors to this shift [19, 20, 33]. Other comorbidities that come with aging, such as hypertension and diabetes type 2, have been relatively uncommon in DMD. Still, physicians treating older patients with DMD will be challenged with a new multi-comorbid panorama as part of the evolving natural history of the disease.

Pneumonia-induced acute respiratory failure was encountered as the leading cause of death in $14 \%$ of the patients 


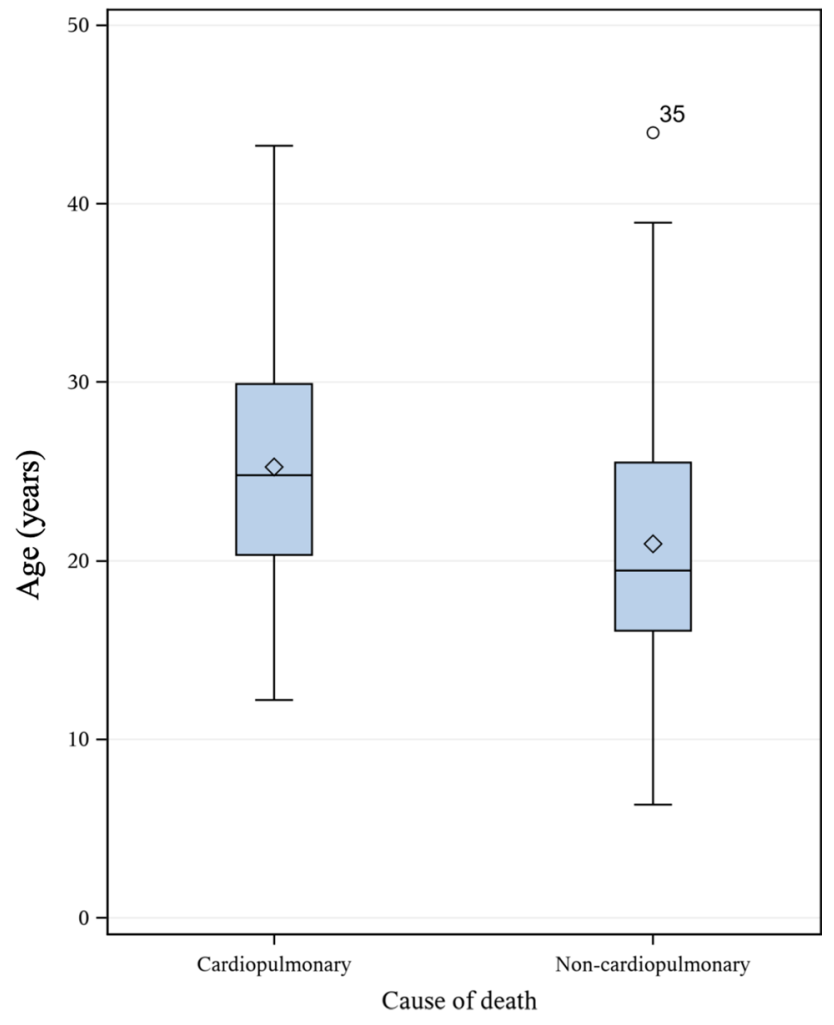

Fig. 4 Differences in age between cardiopulmonary and non-cardiopulmonary causes of death in Swedish deceased DMD patients, born 1970-2019. There is a mean difference of 4.28 years $(95 \%$ CI $1.41-7.33)(p=0.004)$ between cardiopulmonary causes of death with a mean age of 25.2 (SD 6.5) years compared with non-cardiopulmonary causes of death with a mean age of 21.0 (SD 8.2) years. Line in box represents median age and diamond represents mean age. $\mathrm{DMD}=$ Duchenne muscular dystrophy, $\mathrm{CI}=$ Confidence Interval, $\mathrm{SD}=$ Standard Deviation

(incidence 5.8 per 1000 person-years). Chronic bacterial colonization of the upper airways is common among patients with neuromuscular disease, causing airway inflammation and recurrent respiratory tract infections with a significant effect on DMD morbidity and mortality. Adherence with respiratory care guidelines, especially in the setting of acute respiratory illness, although crucial, is lacking [34]. New therapeutic modalities, such as inhaled antibiotics, are emerging in the respiratory management of neuromuscular diseases, potentially changing the respiratory outcomes and related mortality rates.

Our study reports a median life span of 30 years of age, wich is in accordance with other studies of mixed DMD population with different treatment regimes [35]. The increased life span for patients with DMD over time reflects not only the evolution of standards of care in DMD worldwide [6], but also an overall improvement of patient management on a national level. The effect of wheelchair confinement on life expectancy has been debated. We found that age at loss of ambulation does not correlate to the age of death in DMD,

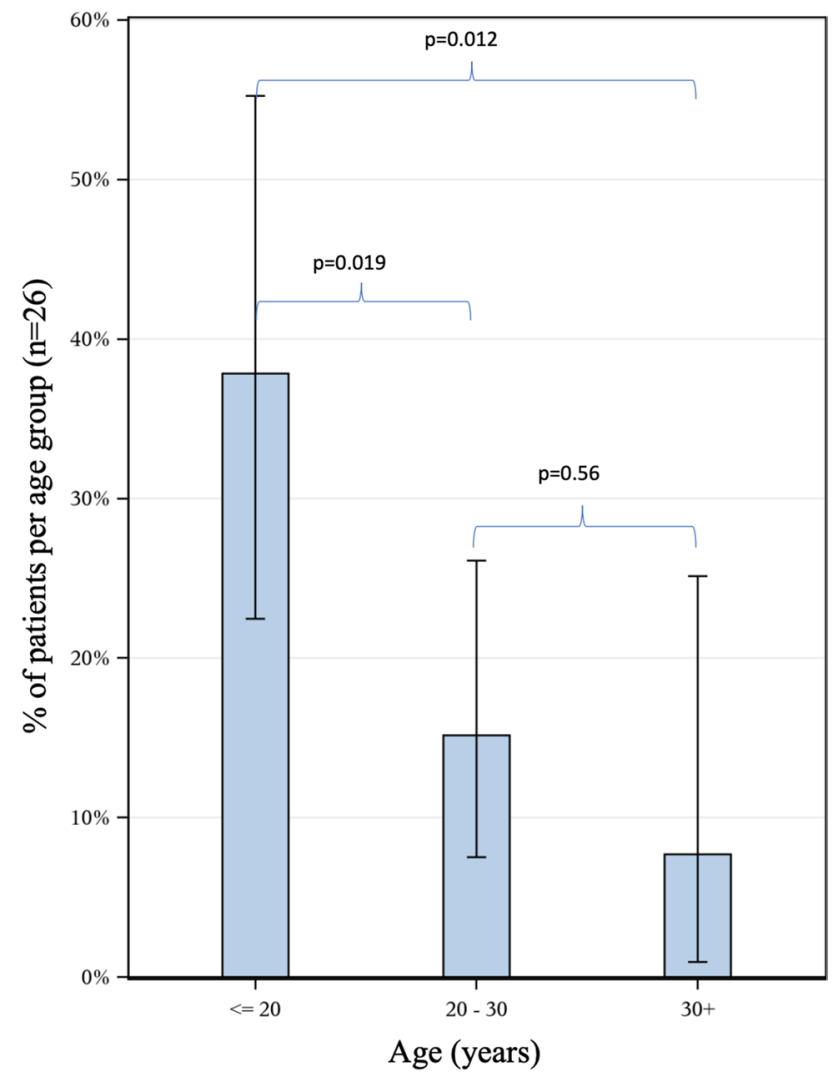

Fig. 5 Barchart of the proportion of Swedish deceased DMD patients, born 1970-2019, with non-cardiopulmonary causes of death in each age class; $<20(\mathrm{n}=14 / 37 ; 37.8 \%$ (CI 95\% 22.5-55.2)), 20-30 $(n=10 / 66 ; 15.2 \%($ CI $95 \% 7.5-26.1))$ and $30+(n=2 / 26 ; 7.7 \%$ (CI 95\% 1.0-25.1)). DMD = Duchenne muscular dystrophy, $\mathrm{n}=$ number, $\mathrm{CI}=$ Confidence Interval

confirming similar observations [32]. Age at loss of ambulation has been considered as an indicator of the disease severity in DMD, and may contribute to other comorbidities, such as progressive scoliosis and pulmonary decline, but has no impact on survival according to our study. The fact that there were no major differences in patient longevity between regions is believed to be the result of a continuous work towards harmonization of care across healthcare providers and regions, as well as the implementation of a follow-up multidisciplinary program in specialized clinics for patients with neuromuscular diseases in Sweden. Harmonization of patient care and access to specialized teams of healthcare professionals is of vital essence not only for DMD but also for all rare diseases, especially in the era of disease-modifying novel therapies that change the natural history of the disease.

A strength of this study is the thorough, multisource patient identification and data collection, which ensured a high calculated birth prevalence of 19.2 and 20.5 per 100,000 male births for patients born 1980-89 and 1990-99. This is, however, a retrospective, nationwide cohort study of patients 
born over the past five decades, generating some limitations worth to be mentioned. First, finding all patients with DMD diagnosis born since 1970 was challenging, especially for patients born during the first study decade. Furthermore, identifying a single leading cause of death in DMD patients was difficult in some cases, as there could be multiple conditions contributing to death, such as a combination of chronic cardiac and pulmonary failure. Moreover, some patients died at home as a result of their chronic condition, without further medical examination or postmortem investigation. To minimize unidentified cases and augment data validity, we have used multiple sources for patient identification and data verification, as well as a standardized methodological approach to determine the leading cause of death, and succeeding to verify the cause of death with medical reports in $83.7 \%$ of the cases; still, few patients and some medical information may have been missed. Patients born before 1980 were not included in the survival analysis. The reason for this is the low calculated birth prevalence for patients born during this decade. Moreover, many of the patients born 1970-79 were identified through Swedevox, suggesting that the majority of these patients had reached an age requiring non-invasive ventilatory support and survival analysis was therefore at risk of being skewed towards older ages.

In conclusion, improvements in the care of patients with DMD have also affected survival and causes of death in a national perspective. The fact that one in five patients with DMD dies from non-cardiopulmonary causes, and that these causes contribute significantly to higher mortality among younger patients with DMD, suggests that deeper research is needed on risk-factor identification and prevention. The changing epidemiology of DMD and the new disease panorama of the growing adult DMD population requires reorientation of health care, both in preventive measures at young ages and tackling new comorbidities in older patients with DMD.

\begin{abstract}
Authors contribution All authors contributed to the study conception and design. Material preparation, data collection and analysis were performed by Lisa Wahlgren and a statistician. The first draft of the manuscript was written by Lisa Wahlgren and Kalliopi Sofou and all authors commented on previous versions of the manuscript. All authors read and approved the final manuscript. Authors Már Tulinius and Kalliopi Sofou share co-last authorship.
\end{abstract}

Funding Open access funding provided by University of Gothenburg. This project has been funded by: The foundation for Bo-Göran Bremert's memory, The foundation of Linnéa and Joseph Carlsson and by the Swedish fundraising foundation for Muscular Dystrophy Research (SMDF).

Availability of data and material Case report form is available upon request.

\section{Declarations}

\section{Conflict of interest None.}

Ethics approval The study protocol was approved by the Swedish Ethics Committee (Dnr. 1130-11 and 2019-01790).

Consent to participate This research study was conducted retrospectively from data obtained from registries and the patients' medical records. The Swedish Ethics Committee decided that informed consent from the families should not be collected.

Consent for publication Not applicable.

Open Access This article is licensed under a Creative Commons Attribution 4.0 International License, which permits use, sharing, adaptation, distribution and reproduction in any medium or format, as long as you give appropriate credit to the original author(s) and the source, provide a link to the Creative Commons licence, and indicate if changes were made. The images or other third party material in this article are included in the article's Creative Commons licence, unless indicated otherwise in a credit line to the material. If material is not included in the article's Creative Commons licence and your intended use is not permitted by statutory regulation or exceeds the permitted use, you will need to obtain permission directly from the copyright holder. To view a copy of this licence, visit http://creativecommons.org/licenses/by/4.0/.

\section{References}

1. Crisafulli S, Sultana J, Fontana A, Salvo F, Messina S, Trifirò G. Global epidemiology of Duchenne muscular dystrophy: an updated systematic review and meta-analysis. Orphanet J Rare Dis. 2020. https://doi.org/10.1186/s13023-020-01430-8.

2. Darin N, Tulinius M. Neuromuscular disorders in childhood: a descriptive epidemiological study from western Sweden. Neuromuscul Disord NMD. 2000. https://doi.org/10.1016/s09608966(99)00055-3.

3. Hoffman EP, Brown RH Jr, Kunkel LM. Dystrophin: the protein product of the Duchenne muscular dystrophy locus. Cell. 1987. https://doi.org/10.1016/0092-8674(87)90579-4.

4. Muntoni F, Torelli S, Ferlini A. Dystrophin and mutations: one gene, several proteins, multiple phenotypes. Lancet Neurol. 2003. https://doi.org/10.1016/s1474-4422(03)00585-4.

5. Dubowitz V. Muscle disorders in childhood. 2nd ed. London: Saunders; 1995.

6. Birnkrant DJ, Bushby K, Bann CM, et al. Diagnosis and management of Duchenne muscular dystrophy, part 1: diagnosis, and neuromuscular, rehabilitation, endocrine, and gastrointestinal and nutritional management. Lancet Neurol. 2018. https://doi.org/10. 1016/s1474-4422(18)30024-3.

7. McDonald CM, Abresch RT, Carter GT, et al. Profiles of neuromuscular diseases. Duchenne muscular dystrophy. Am J Phys Med Rehabil. 1995. https://doi.org/10.1097/00002060-19950 9001-00003.

8. Emery AE. The muscular dystrophies. Lancet. 2002. https://doi. org/10.1016/s0140-6736(02)07815-7.

9. Van Ruiten HJ, Marini Bettolo C, Cheetham T, et al. Why are some patients with Duchenne muscular dystrophy dying young: An analysis of causes of death in North East England. Eur J Paediatr Neurol EJPN. 2016. https://doi.org/10.1016/j.ejpn.2016.07. 020 . 
10. Passamano L, Taglia A, Palladino A, et al. Improvement of survival in Duchenne Muscular Dystrophy: retrospective analysis of 835 patients. Acta Myol. 2012;31(2):121-5.

11. Kieny $\mathrm{P}$, Chollet $\mathrm{S}$, Delalande $\mathrm{P}$, et al. Evolution of life expectancy of patients with Duchenne muscular dystrophy at AFM Yolaine de Kepper centre between 1981 and 2011. Ann Phys Rehabil Med. 2013. https://doi.org/10.1016/j.rehab.2013.06.002.

12. Gozal D. Pulmonary manifestations of neuromuscular disease with special reference to Duchenne muscular dystrophy and spinal muscular atrophy. Pediatr Pulmonol. 2000; https://doi.org/10. 1002/(sici)1099-0496(200002)29:2<141::aid-ppul9>3.0.co;2-y

13. Kaspar RW, Allen HD, Montanaro F. Current understanding and management of dilated cardiomyopathy in Duchenne and Becker muscular dystrophy. J Am Acad Nurse Pract. 2009. https://doi. org/10.1111/j.1745-7599.2009.00404.x.

14. Nigro G, Comi LI, Politano L, Bain RJ. The incidence and evolution of cardiomyopathy in Duchenne muscular dystrophy. Int $\mathrm{J}$ Cardiol. 1990. https://doi.org/10.1016/0167-5273(90)90082-g.

15. Birnkrant DJ, Ararat E, Mhanna MJ. Cardiac phenotype determines survival in Duchenne muscular dystrophy. Pediatr Pulmonol. 2016. https://doi.org/10.1002/ppul.23215.

16. McDonald CM, Henricson EK, Abresch RT, et al. Long-term effects of glucocorticoids on function, quality of life, and survival in patients with Duchenne muscular dystrophy: a prospective cohort study. Lancet. 2018. https://doi.org/10.1016/s01406736(17)32160-8

17. Eagle M, Baudouin SV, Chandler C, Giddings DR, Bullock R, Bushby K. Survival in Duchenne muscular dystrophy: improvements in life expectancy since 1967 and the impact of home nocturnal ventilation. Neuromuscul Disord NMD. 2002. https://doi. org/10.1016/s0960-8966(02)00140-2.

18. Bach JR, Martinez D. Duchenne muscular dystrophy: continuous noninvasive ventilatory support prolongs survival. Respir Care. 2011. https://doi.org/10.4187/respcare.00831.

19. Ishikawa Y, Miura T, Ishikawa Y, et al. Duchenne muscular dystrophy: survival by cardio-respiratory interventions. Neuromuscul Disord NMD. 2011. https://doi.org/10.1016/j.nmd.2010.09.006.

20. Ogata H, Ishikawa Y, Ishikawa Y, Minami R. Beneficial effects of beta-blockers and angiotensin-converting enzyme inhibitors in Duchenne muscular dystrophy. J Cardiol. 2009. https://doi.org/10. 1016/j.jjcc.2008.08.013.

21. Parreira SL, Resende MB, Zanoteli E, Carvalho MS, Marie SK, Reed UC. Comparison of motor strength and function in patients with Duchenne muscular dystrophy with or without steroid therapy. Arq Neuropsiquiatr. 2010. https://doi.org/10.1590/s0004282x2010000500002.

22. Moxley RT 3rd, Pandya S, Ciafaloni E, Fox DJ, Campbell K. Change in natural history of Duchenne muscular dystrophy with long-term corticosteroid treatment: implications for management. J Child Neurol. 2010. https://doi.org/10.1177/0883073810371004.

23. Biggar WD, Harris VA, Eliasoph L, Alman B. Long-term benefits of deflazacort treatment for boys with Duchenne muscular dystrophy in their second decade. Neuromuscul Disord NMD. 2006. https://doi.org/10.1016/j.nmd.2006.01.010.

24. Bello L, Gordish-Dressman H, Morgenroth LP, et al. Prednisone/ prednisolone and deflazacort regimens in the CINRG Duchenne natural history study. Neurology. 2015. https://doi.org/10.1212/ wnl.0000000000001950.

25. Emery AEH. Diagnostic Criteria for Neuromuscular Disorders. 2nd ed. Barn: European Neuromuscular Centre; 1994.

26. Stromberg A, Darin N, Kroksmark A. K. et al. What was the age and cause of death in patients with Duchenne muscular dystrophy in Sweden during 2000-2010? 2012. https://www.sciencedirect. com/science/article/abs/pii/S0960896612004385. Accessed 27 May 2021.

27. Schorling DC, Müller CK, Pechmann A, et al. Coagulation disorders in Duchenne muscular dystrophy? Results of a registrybased online survey. Acta Myol. 2020. https://doi.org/10.36185/ 2532-1900-001.

28. Silverstein MD, Heit JA, Mohr DN, Petterson TM, O'Fallon WM, Melton LJ 3rd. Trends in the incidence of deep vein thrombosis and pulmonary embolism: a 25-year population-based study. Arch Intern Med. 1998. https://doi.org/10.1001/archinte.158.6.585.

29. Nozaki F, Kusunoki T, Kumada T, Shibata M, Fujii T. Risk factors for cerebral infarction in Duchenne muscular dystrophy: review with our 2 cases. J Stroke Cerebrovasc Dis. 2019. https://doi.org/ 10.1016/j.jstrokecerebrovasdis.2019.06.023.

30. Winterholler M, Holländer C, Kerling F, et al. Stroke in Duchenne muscular dystrophy: a retrospective longitudinal study in 54 patients. Stroke. 2016. https://doi.org/10.1161/strokeaha.116. 013678.

31. Rosengren A, Giang KW, Lappas G, Jern C, Torén K, Björck L. Twenty-four-year trends in the incidence of ischemic stroke in Sweden from to 2010. Stroke. 1987. https://doi.org/10.1161/strok eaha.113.001170.

32. Parker AE, Robb SA, Chambers J, et al. Analysis of an adult Duchenne muscular dystrophy population. QJM. 2005. https:// doi.org/10.1093/qjmed/hci113.

33. Buddhe S, Cripe L, Friedland-Little J, et al. Cardiac management of the patient with Duchenne muscular dystrophy. Pediatrics. 2018. https://doi.org/10.1542/peds.2018-0333I.

34. Sheehan DW, Birnkrant DJ, Benditt JO, et al. Respiratory management of the patient with Duchenne muscular dystrophy. Pediatrics. 2018. https://doi.org/10.1542/peds.2018-0333H.

35. Landfeldt E, Thompson R, Sejersen T, McMillan HJ, Kirschner $\mathrm{J}$, Lochmüller H. Life expectancy at birth in Duchenne muscular dystrophy: a systematic review and meta-analysis. Eur J Epidemiol. 2020. https://doi.org/10.1007/s10654-020-00613-8.

Publisher's Note Springer Nature remains neutral with regard to jurisdictional claims in published maps and institutional affiliations. 